\title{
Debilitating consequences of drooling
}

\author{
B. R. Bloem · J. G. Kalf · P. C. M. van de Kerkhof • \\ M. J. Zwarts
}

Received: 3 April 2009/Revised: 14 April 2009/Accepted: 15 April 2009/Published online: 3 May 2009

(C) The Author(s) 2009. This article is published with open access at Springerlink.com

\begin{abstract}
A 71-year-old man with a 13-year history of idiopathic Parkinson's disease (PD) was referred to us because of severe and intractable drooling. His complaints started 4 years earlier with nocturnal drooling, but this had progressed to profuse drooling throughout the day. By that time he also suffered from severely impaired swallowing and severe hypokinetic dysarthria. The corners of his mouth were persistently wet, and this had produced a debilitating dermatitis in the perioral region, which is illustrated in Fig. 1. At investigation we observed erythematous plaques, in part sharply demarcated. The lesions showed some rhagades and mild scaling. Moreover, despite use of handkerchiefs, saliva was constantly dripping onto the patient's clothes and feet, destroying the leather of his
\end{abstract}

B. R. Bloem ( $\square)$

Department of Neurology, Parkinson Centre Nijmegen, Radboud University Nijmegen Medical Centre, PO Box 9101, 6500 HB Nijmegen, The Netherlands e-mail: b.bloem@neuro.umcn.nl

B. R. Bloem · J. G. Kalf

Centre for Neuroscience, Donders Institute of Brain,

Cognition and Behaviour, Nijmegen, The Netherlands

J. G. Kalf

Department of Rehabilitation, Radboud University

Nijmegen Medical Centre, Nijmegen,

The Netherlands

P. C. M. van de Kerkhof

Department of Dermatology, Radboud University Nijmegen

Medical Centre, Nijmegen, The Netherlands

M. J. Zwarts

Department of Clinical Neurophysiology, Radboud University

Nijmegen Medical Centre, Nijmegen, The Netherlands shoes and necessitating him to purchase new shoes every 3 months. Symptomatic treatment with anticholinergics had been tried, but this was stopped because of systemic side effects. Injection of botulinum toxin into the submandibular and parotid glands effectively suppressed saliva production, and the perioral skin lesions improved considerably.

This case history underscores that drooling can have a tremendous impact on the quality of life of affected patients [3]. The exact pathophysiology remains to be determined, but is more likely related to reduced automatic swallowing frequency than to increased production of

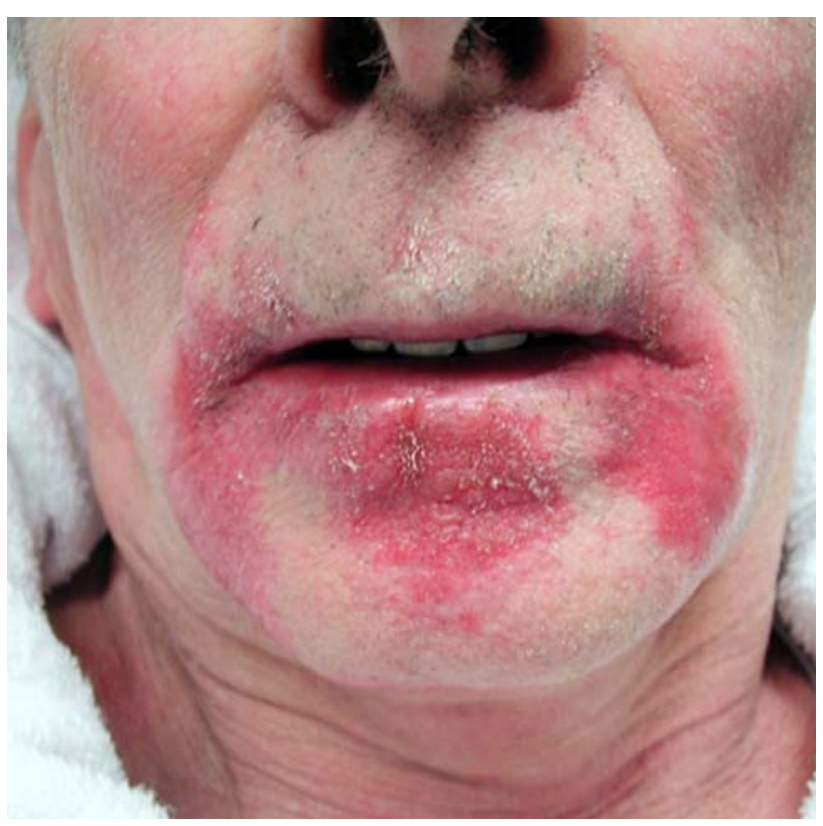

Fig. 1 Prior to botulinum toxin injections into the salivary glands, there was a marked perioral dermatitis 
saliva [4]. Various symptomatic treatments are available, aiming either to reduce saliva production (botulinum toxin, anticholinergics, or radiotherapy over the salivary glands) or to improve the quality and frequency of swallowing $[1,2]$.

Open Access This article is distributed under the terms of the Creative Commons Attribution Noncommercial License which permits any noncommercial use, distribution, and reproduction in any medium, provided the original author(s) and source are credited.

\section{References}

1. Chou KL, Evatt M, Hinson V, Kompoliti K (2007) Sialorrhea in Parkinson's disease: a review. Mov Disord 22:2306-2313. doi: $10.1002 / \mathrm{mds} .21646$
2. Kalf JG, Smit AM, Bloem BR, Zwarts MJ, Mulleners WM, Munneke M (2007) Botulinum toxin A for drooling in Parkinson's disease: a pilot study to compare submandibular to parotid gland injections. Parkinsonism Relat Disord 13:532-534. doi:10.1016/j. parkreldis.2007.01.007

3. Kalf JG, Smit AM, Bloem BR, Zwarts MJ, Munneke M (2007) Impact of drooling in Parkinson's disease. J Neurol 254:12271232. doi:10.1007/s00415-007-0508-9

4. Tumilasci OR, Cersosimo MG, Belforte JE, Micheli FE, Benarroch EE, Pazo JH (2006) Quantitative study of salivary secretion in Parkinson's disease. Mov Disord 21:660-667. doi:10.1002/mds. 20784 